\title{
High flow versus conventional nasal cannula for oxygenation and ventilation maintenance during surgery with intravenous deep sedation by propofol: a randomized controlled study
}

\author{
Amorn Vijitpavan ${ }^{*}$ and Yanin Kooncharoensuk
}

\begin{abstract}
Background: The dead space washout and provision of some level of positive airway pressure by nasal high-flow (NHF) cannula could improve the efficiency of ventilation, oxygenation and maintenance of the upper airway in patients undergoing deep sedation. This study aimed to compare the incidences of events represented oxygenation and ventilation, i.e. desaturation and upper airway obstruction, and arterial blood gas (ABG) levels between using NHF cannula and conventional nasal cannula (NC2) during deep sedation of adult surgical patients.

Methods: In this prospective randomized single-blinded study, the patients who were 20-80 years old, ASA physical status of 1 to 3, scheduled for surgery under intravenous sedation (IVS) were included. The patients were randomly divided into two groups, i.e., NC2 or NHF groups. Propofol infusion was given to maintain deep sedation. The desaturation $\left(\mathrm{SpO}_{2}<92 \%\right)$ and upper airway obstruction events (presence of snoring with paradoxical breathing) after application of NC2 or NHF were observed and collected. Other outcomes included interventions during IVS, such as jaw lifting or airway instrument insertion, mouth dryness, and post- ABG analyses were also collected and compared.

Results: Thirty-six patients undergoing endovascular surgery were randomized into NC2 or NHF groups (18 in each group). No patients dropped out of the study. There were no significant differences in age, sex, ASA physical status, pre-sedation and pre-application of $\mathrm{NC} 2$ and NHF ABG analyses $\left(\mathrm{PaO}_{2}, \mathrm{SaO}_{2}, \mathrm{pH}, \mathrm{PaCO}_{2}\right.$, and $\left.\mathrm{PaO}_{2} / \mathrm{FiO}_{2}\right)$. NHF group had significantly lower in the incidence of desaturation [5 (27.78\%) vs $13(72.22 \%), p=0.008]$, upper airway obstruction [4 (22.22\%) vs 13 (72.22\%), $p=0.003$ ], and airway maneuver [6 (33.33\%) vs 13 (72.22\%), $p=0.019$ ] than NC2 group. There were no differences in the ABG analyses after oxygen supplementation and no significant differences in mouth dryness between groups.

Conclusion: The use of NHF cannula in patients undergoing endovascular surgery under deep sedation reduced desaturation events and required fewer airway interventions than NC2 with no difference in arterial blood gas analyses and mouth dryness.
\end{abstract}

Keywords: High flow, Nasal cannula, Intravenous sedation, Oxygenation, Ventilation, Desaturation

*Correspondence: fluotec@gmail.com

Department of Anesthesiology, Faculty of Medicine Ramathibodi Hospital, Mahidol University, 270 Rama VI Rd, Ratchathewi,

Bangkok 10400, Thailand

\section{Introduction}

Intravenous sedation is widely performed to sedate patients for many pain-free procedures. According to the American Society of Anesthesiologists (ASA), three levels of sedation are defined by responsiveness of the original author(s) and the source, provide a link to the Creative Commons licence, and indicate if changes were made. The images or other third party material in this article are included in the article's Creative Commons licence, unless indicated otherwise in a credit line to the material. If material is not included in the article's Creative Commons licence and your intended use is not permitted by statutory regulation or exceeds the permitted use, you will need to obtain permission directly from the copyright holder. To view a copy of this licence, visit http://creativecommons.org/licenses/by/4.0/. The Creative Commons Public Domain Dedication waiver (http://creativeco mmons.org/publicdomain/zero/1.0/) applies to the data made available in this article, unless otherwise stated in a credit line to the data. 
patient and abilities of the patient to maintain the airways and ventilation. With deep sedation, the upper airway muscles relax and cause upper airway obstruction, which may require some degree of an airway or ventilatory support [1]. Therefore, several techniques, such as chin lift, anterior displacement of the mandible, and airway device insertion, can be applied to improve airway patency [2] Additionally, oxygen supplementation via multiple equipment and positive pressure ventilation via a face mask are performed. Adverse effects from these maneuvers may interrupt the depth of sedation and cause gastric inflation from positive pressure ventilation via a face mask that can lead to nausea or vomiting post-operation. Recently, a nasal high-f low (NHF) cannula was reported to have beneficial effects in patients with obstructive sleep apnea [3], chronic obstructive pulmonary disease [4]. Several studies also demonstrated that the use of an NHF cannula could reduce hypoxia or desaturation events with good tolerance or minimal adverse events in the patients undergoing endoscopic retrograde cholangiography (ERCP) [5], bronchoscopy [6] and gastroscopy [7], and dental treatment [8] under sedation. A previous randomized controlled trial (RCT) showed benefit and safety of the NHF oxygen therapy in hypoxemic patients after receiving cardiothoracic surgery [9] and a prospective cohort studies shown that NHF cannula was a useful tool as an adjuvant or main oxygen therapy during induction of general anesthesia, maintenance of deep intraoperative sedation, and during early postoperative care [10].

An NHF cannula can deliver positive airway pressure (PAP) in the upper airway without the use of an uncomfortable face or nasal mask compared with a conventional PAP machine. Mean nasopharyngeal pressure during NHF therapy increases as flow increases [11] and PAP created by an NHF depends on whether the person is breathing with the mouth open or closed and the flow rate [12]. Hypopharyngeal pressure increases with an increase in gas flow rate. The mean airway pressure is as high as $7.1 \mathrm{cmH}_{2} \mathrm{O}$ when oxygen flow increases to $50 \mathrm{~L} /$ minute [13]. Moreover, patients can comfortably breathe warmed and fully humidified air, even when the flow rate is increased up to $50 \mathrm{~L} /$ minute. The gas could be humidified with a heated water chamber immediately before delivery to the patient [13]. Dead space washout and provision of some level of positive airway pressure by NHF device can improve efficiency of ventilation, oxygenation and self-maintaining of the upper airway [14]. However, there was no randomized controlled studies to demonstrate that NHF could improve oxygenation and ventilation in endovascular surgery patients undergoing intravenous deep sedation when compared with NC2.

Therefore, we conducted a prospective, randomized, controlled trial in inpatients who planned to have surgery under IVS, to demonstrate whether using an NHF cannula was able to maintain oxygenation and ventilation during deep sedation compared with a conventional nasal cannula (NC2) at the same fraction of inspired oxygen $\left(\mathrm{FiO}_{2}\right)$.

\section{Methods \\ Study design and participants}

This prospective single-blinded randomized controlled study was approved by the Committee on Human Rights Related to Research Involving Human Subjects, Faculty of Medicine Ramathibodi Hospital, Mahidol University (Approval Certificate ID: MURA 2017/90. Protocol ID 02-60-12, approval on 30/03/2017). The study was registered on Thai Clinal Trial Registry http://www.clinicaltr ials.in.th (Study ID: TCTR20201007002, Registration date $01 / 11 / 2018$ ). This study was retrospectively registered in the registry because it was not a requirement for the approval of the protocol by the Committee on Human Rights Related to Research Involving Human Subjects of the Faculty of Medicine. The study was carried out in accordance with the Declaration of Helsinki and the Conference on Harmonization Guidelines for Good Clinical Practice and adhered to Consolidated Standards of Reporting Trials (CONSORT) guidelines [15].

Written informed consent was obtained from all participants prior to participation in this study. We recruited 20-80-year-old patients with an American Society of Anesthesiologists (ASA) physical status classification of 1 to 3 who were scheduled for surgery under IVS. The patients with known allergies to the anesthetic drugs used in the study and those with known unstable hemodynamics were excluded from the study.

Eligible patients were randomly divided into 2 groups. The patients in Group 1 received conventional nasal cannula with oxygen flow at $2 \mathrm{~L} /$ minute (Fraction of inspired oxygen $\left(\mathrm{FiO}_{2}\right): 0.28 ; \mathrm{NC} 2$ group) while the patients in Group 2 were administered nasal high flow (NHF) (Optiflow; Fisher \& Paykel Healthcare, Auckland, New Zealand) therapy at a flow rate of $60 \mathrm{~L} /$ minute $\left(\mathrm{FiO}_{2}: 0.28\right.$; NHF group). All gases for patients using an NHF cannula were administered through a humidifier and breathing circuits (AIRVO ${ }^{\mathrm{TM}} 2$ System; Fisher \& Paykel Healthcare). The randomization was performed with sealed envelope randomization services (available at http://www.seale denvelope.com) with allocation ratio of 1:1 and block size of 2 .

\section{Anesthesia and measurements}

The primary outcome was the occurrence of desaturation defined as an $\mathrm{SpO}_{2} \leq 92 \%$ (measured by pulse oximetry) after application of NC2 or NHF. The secondary outcomes were the occurrence of upper airway obstruction 
event defined as the present of snoring with paradoxical breathing, interventions during IVS, such as jaw lifting or airway instrument insertion, and arterial blood gas analyses after application of NC2 or NHF, and mouth dryness.

For anesthesia, an intravenous catheter was inserted with any sized catheter and Acetate Ringer's solution was started at $60 \mathrm{~mL} / \mathrm{kg}$. Routine monitoring included noninvasive blood pressure, pulse rate, and pulse oximetry $\left(\mathrm{SpO}_{2}\right)$, and electrocardiography (lead II) was performed before induction of anesthesia. Before starting sedation, an arterial line was inserted into a radial artery under local anesthesia (with 1\% lidocaine without adrenaline) and then the first arterial blood sample was collected. The patient's head was then repositioned by using rolled drapes to support the posterior neck and shoulder. Subsequently, hypnosis was induced by the administration of propofol using a target-controlled infusion system. The target blood concentration was maintained at $2 \mu \mathrm{g} / \mathrm{mL}$ to obtain an adequate deep level of sedation [16, 17]. The second arterial blood sample was then collected $15 \mathrm{~min}$ after propofol infusion to ensure the adequate depth of sedation. Administration of oxygen was initiated via NC2 or NCF cannula depending on the group assigned after an adequate depth of sedation was achieved. The definition of deep sedation was that the patients cannot be easily aroused but still had respond purposefully following repeated or painful stimulation [1]. In this study, we assessed the deep sedation by using verbal commands and shaking shoulders. The deeply sedated patients must not have any response to verbal commands but still have a response to shaking shoulders. The deep sedation was periodically assessed throughout the surgical procedure. The third arterial blood sample was collected after applying oxygen for $15 \mathrm{~min}$. The response to surgical painful stimuli was got rid by infiltrating with $10 \mathrm{ml}$ of $1 \%$ xylocaine at surgical site.

Anesthesiologists carefully monitored for upper airway obstruction by listening to breathing sounds and observing chest wall movement. Systolic and diastolic blood pressure, heart rate, and arterial hemoglobin saturation $\left(\mathrm{SpO}_{2}\right)$ were measured and recorded every 5 min throughout the study. When systolic blood pressure decreased by $20 \%$ from baseline or was less than $100 \mathrm{mmHg}, 3$ to $6 \mathrm{mg}$ of ephedrine was administrated. When $\mathrm{SpO}_{2}$ decreased below 92\%, an intervention, such as jaw lifting or anterior mandibular displacement, was performed by the anesthesiologist and recorded. If $\mathrm{SpO}_{2}$ was still less than $90 \%$ in any period of interventions, oxygen was applied by a nasal cannula/NHF cannula or $\mathrm{FiO}_{2}$ was temporarily increased in case of both devices already be used. An oropharyngeal/nasopharyngeal airway was inserted when the upper airways could not be maintained by both devices. A nasopharyngeal airway was used first, and if upper airway obstruction still occurred, an oropharyngeal airway was applied. Positive pressure ventilation (PPV) via a face mask was performed when $\mathrm{SpO}_{2}$ was less than $88 \%$. Taking blood samples was delayed for 15 min after positive ventilation and/or increased $\mathrm{FiO}_{2}$ was intervened. The target blood concentration was not changed until the surgical procedure was completed. Finally, the patients' mouth dryness was evaluated by an interview while the patients did not know which study group they were in.

\section{Statistical analysis}

The approximate rate of desaturation under intravenous sedation in a previous study was $40 \%[5,18]$ in the patients receiving oxygen through conventional nasal cannula. The desaturation rates in the patients receiving oxygen through the nasal high-flow system during sedation in various condition from previous studies were ranged 0 to approximately $20 \%[5,6,19,20]$. We expected that the incidence of desaturation under the intravenous deep sedation in our study would be $40 \%$ in NC2 group and 2\% in NHF group. Power and Sample Size Calculation Program (PS) version 3.1.2 was used to estimate the sample size with the ratio of NC5 to NHF subjects of 1:1. At least 17 subjects in each group were needed to be able to reject the null hypothesis that the desaturation rate during IVS between NC2 and NHF groups are equal with a power of $80 \%$ and a type I error probability of 0.05 . Considering a dropout rate of $5 \%$ due to short term follow-up, the sample size required was 18 patients per group.

All analyses were performed on an intention-to-treat basis using IBM SPSS Statistics for Windows, Version 20.0. (IBM Corp, Armonk, NY, USA). Baseline categorical characteristics are described as number with percentage and/or 95\% confidence interval $(95 \% \mathrm{CI})$ and the quantitative variables as mean \pm standard deviation (SD). Dichotomous variables were compared with the $\chi^{2}$ test or Fisher's test, as appropriate. Continuous variables were compared with the t-test or Wilcoxon rank-sum test as appropriate. A $P$-value of less than 0.05 was considered statistically significant for all tests.

\section{Results}

\section{Baseline demographic and clinical characteristics}

From April 2017 to February 2018, there were 36 eligible patients scheduled for surgical treatment under IVS. All patients screened and enrolled were patients undergoing endovascular surgery. The patients were randomized to either $\mathrm{NC} 2$ or NHF group using an equal allocation. No patients dropped out of the study (Fig. 1 Participant Flow). Thus, all randomized patients 
were included in the analyses. There were no significant differences in age, sex, male/female, body mass index, ASA physical status, having obstructive sleep apnea, and pre-sedation blood gases between the two groups (Table 1).

\section{Outcomes}

NC2 group had a significantly higher incidence of desaturation than the NHF group [13 (72.22\%) vs. 5 (27.78\%); $p=0.008$ ]. Besides, there was a significantly higher incidence of upper airway obstruction in the NC2 group than in the NHF group [13 (72.22\%) vs. 4 (22.22); $p=0.003$ ]. The NC2 group required interventions more frequently when compared with the NHF group. However, there

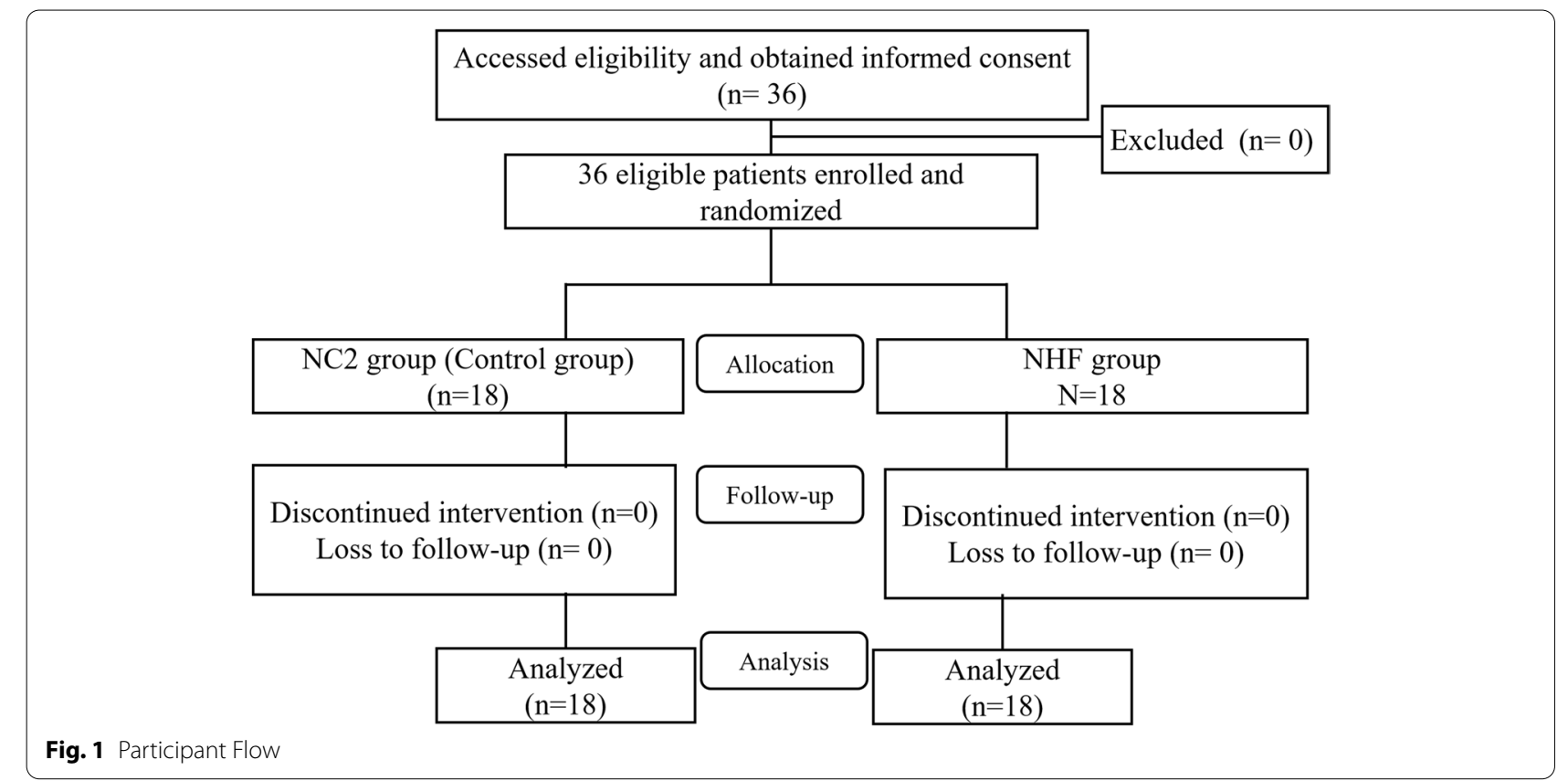

Table 1 Baseline characteristics

\begin{tabular}{|c|c|c|c|}
\hline & NC2 group $(n=18)$ & NHF group $(n=18)$ & $P$ value \\
\hline Age (years) & $67.33 \pm 8.83$ & $67.44 \pm 12.84$ & 0.976 \\
\hline Sex, male/female, $n$ & $11 / 7$ & $11 / 7$ & 1.000 \\
\hline Body mass index $\left(\mathrm{kg} / \mathrm{m}^{2}\right)$ & $22.85 \pm 3.38$ & $24.29 \pm 4.56$ & 0.291 \\
\hline ASA physical status & & & 1.000 \\
\hline । & $1(5.56 \%)$ & $1(5.56 \%)$ & \\
\hline$\|$ & $1(5.56 \%)$ & $1(5.56 \%)$ & \\
\hline III & $16(88.89 \%)$ & $16(88.89 \%)$ & \\
\hline Obstructive sleep apnea & $1(5.56 \%)$ & $0(0 \%)$ & 1.000 \\
\hline \multicolumn{4}{|l|}{ Pre-sedation blood gases } \\
\hline $\mathrm{pH}$ & $7.45 \pm 0.03$ & $7.42 \pm 0.07$ & 0.121 \\
\hline $\mathrm{PaCO}_{2}$ & $38.15 \pm 3.25$ & $40.34 \pm 4.13$ & 0.086 \\
\hline $\mathrm{PaO}_{2}$ & $78.81 \pm 16.88$ & $79.37 \pm 12.87$ & 0.912 \\
\hline $\mathrm{SaO}_{2}$ & $95.78 \pm 1.93$ & $96.49 \pm 2.61$ & 0.359 \\
\hline $\mathrm{PaO}_{2} / \mathrm{FiO}_{2}$ & $368.85 \pm 84.5$ & $372.08 \pm 63.41$ & 0.898 \\
\hline Endovascular surgery, n (\%) & $18(100 \%)$ & $18(100 \%)$ & NA \\
\hline
\end{tabular}

Data are mean \pm standard deviation or $\mathrm{n}(\%)$

Abbreviations: NA Not applicable, NHF Nasal high flow, $\mathrm{NC2}$ Conventional nasal cannula, $\mathrm{PaCO}_{2}$ Partial pressure of carbon dioxide in arterial blood, $\mathrm{PaO}{ }_{2}$ Partial pressure of oxygen in arterial blood, $\mathrm{SaO}_{2}$ Oxygen saturation in arterial blood, $\mathrm{FiO}_{2}$ Fraction of inspired oxygen, $\mathrm{FiO}_{2}$ Fraction of inspired oxygen 
was no statistically significant difference in instrument insertion between groups. One of 18 patients in the NHF group required PPV via a face mask during IVS. There was no significant difference in the rate of mucosal dryness between the two groups (Table 2).

The arterial partial pressure of oxygen $\left(\mathrm{PaO}_{2}\right)$ and the $\mathrm{PaO}_{2} / \mathrm{FiO}_{2}$ (PF ratio) after oxygen supplementation were not significantly different between the two groups. The partial pressure of carbon dioxide $\left(\mathrm{PaCO}_{2}\right)$ was also not significantly different between the groups (Table 3 ).

\section{Discussion}

In this study, we used propofol infusion to maintain deep sedation during endovascular surgery. Relaxation of the tongue and pharyngeal muscles causes narrowing or closing of the upper airway space, resulting in upper airway obstruction in patients under deep sedation. Although a

Table 2 Complications, airway intervention and instrument insertion

\begin{tabular}{|c|c|c|c|}
\hline & NC2 group $(n=18)$ & NHF group $(n=18)$ & $P$ value \\
\hline \multicolumn{4}{|l|}{ Complications } \\
\hline Desaturation $\left(\mathrm{SpO}_{2}<92 \%\right)$ during IVS & $\begin{array}{l}13(72.22 \%) \\
{[46.52,90.31 \%]}\end{array}$ & $\begin{array}{l}5(27.78 \%) \\
{[9.69,53.48]}\end{array}$ & $0.008^{*}$ \\
\hline Upper airway obstruction during IVS ${ }^{b}$ & $\begin{array}{l}13(72.22 \%) \\
{[46.52,90.31 \%]}\end{array}$ & $\begin{array}{l}4(22.22 \%) \\
{[6.41,47.63 \%]}\end{array}$ & $0.003^{*}$ \\
\hline Mucosal dryness & $\begin{array}{l}2(11.11 \%) \\
{[1.38,34.71 \%]}\end{array}$ & $\begin{array}{l}1(5.56 \%) \\
{[0.14,27.29 \%]}\end{array}$ & 1.000 \\
\hline \multicolumn{4}{|l|}{ Required interventions } \\
\hline Airway maneuver ${ }^{c}$ & $\begin{array}{l}13(72.22 \%) \\
{[46.52,90.31 \%]}\end{array}$ & $\begin{array}{l}6(33.33 \%) \\
{[13.34,59.01 \%]}\end{array}$ & $0.019^{*}$ \\
\hline PPV requirement ${ }^{c}$ & $0(0 \%)$ & $\begin{array}{l}1(5.56 \%) \\
{[0.14,27.29 \%]}\end{array}$ & 1.000 \\
\hline \multicolumn{4}{|l|}{ Instrument insertion } \\
\hline Nasopharyngeal airway & $\begin{array}{l}6(33.33 \%) \\
{[13.34,59.01 \%]}\end{array}$ & $\begin{array}{l}3(16.67 \%) \\
{[3.58,41.41 \%]}\end{array}$ & 0.443 \\
\hline Oropharyngeal airway & $\begin{array}{l}2(11.11 \%) \\
{[1.38,34.71 \%]}\end{array}$ & $\begin{array}{l}1(5.56 \%) \\
{[0.14,27.29 \%]}\end{array}$ & 1.000 \\
\hline
\end{tabular}

Parentheses are percentages and values in square brackets represent $95 \%$ confidence interval (CI)

Abbreviations: IVS Intravenous sedation (IVS), PPV Positive pressure ventilation

* Significant at $P$ value $<0.05$

${ }^{a}$ Desaturation events after application of NC or NHF during deep sedation

${ }^{\mathrm{b}}$ Upper airway obstruction after application of NC or NHF during deep sedation. The Upper airway obstruction during IVS defined as the present of snoring with paradoxical breathing

${ }^{C}$ One patient in NHF group received airway maneuver with PPV without desaturation and upper airway obstruction during IVS because the patient had apnea

Table 3 Arterial blood gas analysis between groups ( $n=18$ in each group)

\begin{tabular}{|c|c|c|c|c|c|c|c|c|}
\hline & \multicolumn{2}{|l|}{ Baseline } & \multicolumn{3}{|l|}{ Post-sedation $^{a}$} & \multicolumn{3}{|c|}{$\begin{array}{l}\text { Post-sedation with oxygen device } \\
\text { intervention }^{\text {b }}\end{array}$} \\
\hline & NC2 group & NHF group & NC2 group & NHF group & $P$ value & NC2 group & NHF group & $P$ value \\
\hline $\mathrm{PaO}_{2}$ & $78.81 \pm 16.88$ & $79.37 \pm 12.87$ & $63.14 \pm 14.75$ & $62.56 \pm 25.12$ & 0.934 & $110.16 \pm 52.77$ & $109.32 \pm 28.67$ & 0.954 \\
\hline $\mathrm{SaO}_{2}$ & $95.78 \pm 1.93$ & $96.49 \pm 2.61$ & $90.54 \pm 5.88$ & $87.45 \pm 12.24$ & 0.344 & $95.97 \pm 3.72$ & $97.34 \pm 2.51$ & 0.205 \\
\hline $\mathrm{pH}$ & $7.45 \pm 0.03$ & $7.42 \pm 0.07$ & $7.41 \pm 0.06$ & $7.4 \pm 0.06$ & 0.394 & $7.38 \pm 0.04$ & $7.38 \pm 0.05$ & 0.705 \\
\hline $\mathrm{PaCO}_{2}$ & $38.15 \pm 3.25$ & $40.34 \pm 4.13$ & $42.48 \pm 3.67$ & $44.84 \pm 4.79$ & 0.107 & $45.35 \pm 5.69$ & $46.18 \pm 5.56$ & 0.660 \\
\hline $\mathrm{PaO}_{2} / \mathrm{FiO}_{2}$ & $368.85 \pm 84.5$ & $372.08 \pm 63.41$ & $296.15 \pm 71.07$ & $293.21 \pm 119.85$ & 0.929 & $379.34 \pm 183.11$ & $385.71 \pm 105.43$ & 0.899 \\
\hline
\end{tabular}

Data are mean \pm standard deviation (SD)

Abbreviations: NHF Nasal high flow, $\mathrm{NC2}$ Conventional nasal cannula, $\mathrm{PaCO}_{2}$ Partial pressure of carbon dioxide in arterial blood, $\mathrm{PaO}{ }_{2}$ Partial pressure of oxygen in arterial blood, $\mathrm{SaO}_{2}$ Oxygen saturation in arterial blood, $\mathrm{FiO}_{2}$ Fraction of inspired oxygen, $\mathrm{FiO}_{2}$ Fraction of inspired oxygen

a Blood collection $15 \mathrm{~min}$ after propofol infusion and before application of nasal conventional or NHF cannula

${ }^{\mathrm{b}}$ After application of $\mathrm{NC2}$ or $\mathrm{NHF}$ 
simple airway maneuver, such as head tilt, chin lift, or jaw thrust, may be effective to relieve this obstruction, it is often inconvenient to perform during the surgical period. In our study, the NHF system helped reduce the need to open airway obstruction and reduce the incidence of desaturation compared with a conventional nasal cannula. Improving gas exchange could be achieved by an NHF cannula-induced reduction in rebreathed $\mathrm{CO}_{2}$ volume by clearance of dead space $[21,22]$ and an increase in end-expiratory lung volume [23].

NHF can also generate PAP. Many studies on NHF cannulas have shown that this device could generate mean pressure in the pharyngeal space up to $7.1 \mathrm{cmH}_{2} \mathrm{O}$ when flow was delivered up to $50 \mathrm{~L} /$ minute $[11-13,24]$. In this study, the NHF group were administered at a flow rate of $60 \mathrm{~L} /$ minute that higher than the previous studies $[11-13,24]$. The higher rate might be helpful in relieving upper airway obstruction and reduce the requirement for performing airway maneuvers in deeply sedated patients in NHF group. The Starling resistor model of the upper airway is used to explain the collapsible (pharyngeal) segment between two rigid tubes (nasal and trachea) [25]. If the airway pressure in upstream is more than critical closing pressure (pressure required to collapse the airway), the obstruction will be relieved and airflow can pass through the lower airways. The study by Lin Y et al. [7] in outpatients undergoing routine gastroscopy with propofol sedation that used the nasal high flow (NHF) therapy at the flow rate up to $60 \mathrm{~L} /$ minute showed the incidence of hypoxia of $0 \%$ in NHF group while the desaturation rate in NHF group in the present study was $27.78 \%$. The higher desaturation rate might be from the differences in oxygen concentration $\left(\mathrm{FiO}_{2}\right)$ and patient positioning. $\mathrm{FiO}_{2}$ in our study was 0.28 and all patients were in supine position, whereas the study by Lin et al. applied $\mathrm{FiO}_{2}$ of 1.0 and all patients were in lateral position. In addition, the study patient characteristics were also different. Almost all patients in our study were ASA physical status grade 3 while the study by Lin $\mathrm{Y}$ et al. included the patients with ASA physical status grade 1 to 2 only.

A previous study [26] showed that an upstream pressure equal to $11.8 \pm 2.7 \mathrm{cmH}_{2} \mathrm{O}$ was sufficient to maintain airway patency. Mathru $\mathrm{M}$ et al. found that nasal continuous PAP (CPAP) can restore the patency of the pharyngeal airway in patients sedated with propofol [27]. In our study, there were $6 / 18$ patients in the NHF group required an airway maneuver. A reason of airway maneuver requirements could be from insufficient PAP level generated by NHF to open the collapsed airway, which might require upstream pressure of more than 12 $\mathrm{cmH}_{2} \mathrm{O}$, as mentioned above. The PAP created by NHF depends on whether the person is breathing with the mouth opened or closed and the flow rate used.
In this study, there was no control of the mouth position. Additionally, because sedated patients might have had some mechanical obstruction at the nasopharynx, base of the tongue, and hypopharynx, the NHF could not combat the resistance from those obstructions. Therefore, the airflow proximally leaked from the airway obstruction area. Subsequently, the NHF system was unable to maintain PAP all of the time. In the present study, although the incidence of desaturation and upper airway obstruction in NHF group was significantly lower than NC2 group, however, some patients in NHF group required combination of the interventions. Of the 5 patients having desaturation in NHF group, 3 patients had airflow leak and required both the airway maneuver and airway instrument insertion to maintain $\mathrm{SpO}_{2}$ over $92 \%$. Two of the 3 patients required nasopharyngeal airway insertion only and one patient needed both nasopharyngeal and oropharyngeal airway insertion. In addition, one patient in NHF group experienced apnea during the deep sedation. Recent studies demonstrated that transnasal humidified rapid insufflation ventilatory exchange (THRIVE), an oxygenation technique that delivers continuous, warm and humidified oxygen at a high flow rate (up to $120 \mathrm{~L} \mathrm{~min}^{-1}$ ) [28] via high flow nasal cannula could prolong the safe apnea time both adults [29] and children [30]. The THRIVE technique is easily implemented method to achieve oxygenation and ventilation without an invasive device [31]. Further research into THRIVE by comparing with current oxygenation technique with NHF cannula is required to demonstrate the benefit of THRIVE in the patients undergoing surgery under deep sedation.

In this study, post-intervention arterial blood gas analysis showed no significant difference in partial pressure of oxygen $\left(\mathrm{PaO}_{2}\right)$ and carbondioxide $\left(\mathrm{PaCO}_{2}\right)$ between using the NHF system and a conventional nasal cannula. Although $\mathrm{PaO}_{2}$ and $\mathrm{PaCO}_{2}$ were not correlated with clinical desaturation and the need to perform airway interventions, which had a significantly higher incidence in the NC2 group than in the NHF group. The reason for this finding could be because there were patients with severe hypoxemia in the NC2 group. Therefore, we had to prevent further desaturation by performing an airway maneuver and inserting an airway device before collecting blood samples. For this reason, an accurate measurement of oxygenation and ventilation could not be obtained at this time.

In the NC2 group, two patients had an extremely high $\mathrm{PaO}_{2}$ and PF ratio, which caused an increase in overall oxygenation. As a result, oxygenation in the $\mathrm{NC} 2$ group was not significantly different compared with that in the NHF group. Generally, a conventional nasal cannula should only be used with an oxygen flow rate of 
$6 \mathrm{~L} /$ minute because exceeding $6 \mathrm{~L} /$ minute causes dryness of the nasal mucosa. A previous study reported that an oxygen flow rate of up to $50 \mathrm{~L} /$ minute could be delivered by a conventional nasal cannula, but only when the gas was optimally warmed and humidified [32]. In our study, only one patient complained about airway dryness, and it did not lead to low satisfaction by the patient while he was applied oxygen via an NHF cannula.

A previous randomized controlled study showed benefit and safety of the NHF oxygen therapy in hypoxemic patients after receiving cardiothoracic surgery [9] and a prospective cohort studies shown that NHF cannula was a useful tool as an adjuvant or main oxygen therapy during induction of general anesthesia, maintenance of deep intraoperative sedation, and during early postoperative care [10]. However, our study would be the first randomized controlled study comparing nasal high flow cannula versus conventional nasal cannula in the patients undergoing endovascular under IVS. Although the sample size was small, the significant differences in desaturation, upper airway obstruction, and airway maneuver were detected. The study with larger sample size could give more precise estimates of effects (narrower confidence intervals). Despite the positive results, this study has some limitations. We could not properly control the timing of drawing arterial blood gas because of ethical issues about the safety of patients after desaturation occurred. The apnea time and the length of desaturation was not collected and the screening tools for the risk of obstructive sleep apnea (OSA) e.g., STOP-Bang Questionnaire was not applied. Moreover, further studies should measure the nasopharyngeal pressure to clarify if the NHF system was able to maintain PAP or not.

In conclusion, the use of NHF cannula in patients undergoing endovascular surgery under deep sedation reduced desaturation events and required fewer airway interventions than $\mathrm{NC} 2$ with no difference in arterial blood gas analyses and mouth dryness.

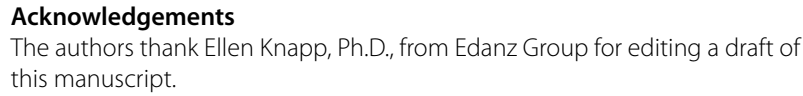

\section{Authors' contributions}

AV devised the study and the main conceptual ideas. Both AV and YK equally contributed to the design and implementation of the research, to the analysis of the results, and the writing of the manuscript. (Contribution: AV: YK, 50:50). The author(s) read and approved the final manuscript.

\section{Funding}

The authors received no specific funding for this work.

\section{Availability of data and materials}

The unidentifiable datasets used and/or analyzed during the current study are available from the corresponding author on reasonable request.

\section{Declarations}

\section{Ethics approval and consent to participate}

This study was approved by the Committee on Human Rights Related to Research Involving Human Subjects, Faculty of Medicine Ramathibodi Hospital, Mahidol University (Approval Certificate ID: MURA 2017/90. Protocol ID 02-60-12, approval on 30/03/2017). Written informed consent was obtained from all participants prior to participation in this study.

\section{Consent for publication}

Not applicable.

\section{Competing interests}

The authors declare that they have no competing interests.

Received: 23 October 2020 Accepted: 8 August 2021

Published online: 04 September 2021

\section{References}

1. Committee on Quality Management and Departmental Administration. Continuum of depth of sedation: definition of general anesthesia and levels of sedation/analgesia. Washington D.C.: American Society of Anesthesiologists (ASA); 1999. [updated 2014 Oct 15]. Available at: http:// www.asahq.org/quality-and-practice-management/standards-guide lines-and-related-resources/continuum-of-depth-of-sedation-definitionof-general-anesthesia-and-levels-of-sedation-analgesia. Accessed 2 July 2018.

2. Becker DE, Haas DA. Recognition and management of complications during moderate and deep sedation part 1: respiratory considerations. Anesth Prog. 2011;58(2):82-92.

3. McGinley B, Halbower A, Schwartz AR, Smith PL, Patil SP, Schneider H. Effect of a high-flow open nasal cannula system on obstructive sleep apnea in children. Pediatrics. 2009;124(1):179-88.

4. Fraser JF, Spooner AJ, Dunster KR, Anstey CM, Corley A. Nasal high flow oxygen therapy in patients with COPD reduces respiratory rate and tissue carbon dioxide while increasing tidal and end-expiratory lung volumes: a randomised crossover trial. Thorax. 2016;71(8):759-61.

5. Cha B, Lee M-J, Park J-S, Jeong S, Lee DH, Park TG. Clinical efficacy of highflow nasal oxygen in patients undergoing ERCP under sedation. Sci Rep. 2021;11(1):350.

6. Douglas N, Ng I, Nazeem F, Lee K, Mezzavia P, Krieser R, Steinfort D, Irving $L$, Segal R. A randomised controlled trial comparing high-flow nasal oxygen with standard management for conscious sedation during bronchoscopy. Anaesthesia. 2018;73(2):169-76.

7. Lin Y, Zhang X, Li L, Wei M, Zhao B, Wang X, Pan Z, Tian J, Yu W, Su D. Highflow nasal cannula oxygen therapy and hypoxia during gastroscopy with propofol sedation: a randomized multicenter clinical trial. Gastrointest Endosc. 2019;90(4):591-601.

8. Sago T, Harano N, Chogyoji Y, Nunomaki M, Shiiba S, Watanabe S. A nasal high-flow system prevents hypoxia in dental patients under intravenous sedation. J Oral Maxillofac Surg. 2015;73(6):1058-64.

9. Stéphan F, Barrucand B, Petit P, Rézaiguia-Delclaux S, Médard A, Delannoy B, Cosserant B, Flicoteaux G, Imbert A, Pilorge C, et al. High-flow nasal oxygen vs noninvasive positive airway pressure in hypoxemic patients after cardiothoracic surgery: a randomized clinical trial. JAMA. 2015;313(23):2331-9.

10. Carullo PC, Phillips DP, Abuelkasem E, Hilmi IA. The perioperative application of high flow nasal cannula: a single center experience. J Anesth Crit Care Open Acess. 2020;12(1):1-5.

11. Parke RL, Eccleston ML, McGuinness SP. The effects of flow on airway pressure during nasal high-flow oxygen therapy. Respir Care. 2011;56(8):1151-5.

12. Groves N, Tobin A. High flow nasal oxygen generates positive airway pressure in adult volunteers. Aust Crit Care. 2007;20(4):126-31.

13. Ritchie JE, Williams AB, Gerard C, Hockey H. Evaluation of a humidified nasal high-flow oxygen system, using oxygraphy, capnography and measurement of upper airway pressures. Anaesth Intensive Care. 2011;39(6):1103-10. 
14. Cortegiani A, Accurso G, Mercadante S, Giarratano A, Gregoretti C. High flow nasal therapy in perioperative medicine: from operating room to general ward. BMC Anesthesiol. 2018;18(1):166.

15. Schulz KF, Altman DG, Moher D. CONSORT 2010 statement: updated guidelines for reporting parallel group randomised trials. BMJ. 2010;340:c332.

16. Barakat AR, Sutcliffe N, Schwab M. Effect site concentration during propofol TCl sedation: a comparison of sedation score with two pharmacokinetic models. Anaesthesia. 2007:62(7):661-6.

17. Milne SE, Troy A, Irwin MG, Kenny GNC. Relationship between bispectral index, auditory evoked potential index and effect-site EC50 for propofol at two clinical end-points. Br J Anaesth. 2003;90(2):127-31.

18. Benatar PF, Galaviz ODA, Chávez RMA, Olivares MH. High-flow nasal cannula versus conventional oxygen therapy for patients undergoing gastrointestinal endoscopy. An Med Asoc Med Hosp ABC. 2017;62(3):187-91.

19. Rozario L, Sloper D, Sheridan MJ. Supplemental oxygen during moderate sedation and the occurrence of clinically significant desaturation during endoscopic procedures. Gastroenterol Nurs. 2008:31 (4):281-5.

20. Teng W-N, Ting CK, Wang Y-T, Hou M-C, Chang W-K, Tsou M-Y, Chiang H, Lin C-L. High-flow nasal cannula and mandibular advancement bite block decrease hypoxic events during sedative esophagogastroduodenoscopy: a randomized clinical trial. Biomed Res Int. 2019;2019:4206795.

21. Dysart K, Miller TL, Wolfson MR, Shaffer TH. Research in high flow therapy: mechanisms of action. Respir Med. 2009:103(10):1400-5.

22. Möller W, Celik G, Feng S, Bartenstein P, Meyer G, Oliver E, Schmid O, Tatkov S. Nasal high flow clears anatomical dead space in upper airway models. J Appl Physiol (1985). 2015;118(12):1525-32.

23. Corley A, Caruana LR, Barnett AG, Tronstad O, Fraser JF. Oxygen delivery through high-flow nasal cannulae increase end-expiratory lung volume and reduce respiratory rate in post-cardiac surgical patients. Br J Anaesth. 2011:107(6):998-1004

24. Parke R, McGuinness S, Eccleston M. Nasal high-flow therapy delivers low level positive airway pressure. Br J Anaesth. 2009;103(6):886-90.
25. Hillman DR, Platt PR, Eastwood PR. The upper airway during anaesthesia. Br J Anaesth. 2003;91(1):31-9.

26. Eastwood PR, Szollosi I, Platt PR, Hillman DR. Collapsibility of the upper airway during anesthesia with isoflurane. Anesthesiology. 2002;97(4):786-93.

27. Mathru M, Esch O, Lang J, Herbert ME, Chaljub G, Goodacre B, vanSonnenberg E. Magnetic resonance imaging of the upper airway. Effects of propofol anesthesia and nasal continuous positive airway pressure in humans. Anesthesiology. 1996;84(2):273-9.

28. Huang L, Dharmawardana N, Badenoch A, Ooi EH. A review of the use of transnasal humidified rapid insufflation ventilatory exchange for patients undergoing surgery in the shared airway setting. J Anesth. 2020;34(1):134-43.

29. Patel A, Nouraei SA. Transnasal Humidified Rapid-Insufflation Ventilatory Exchange (THRIVE): a physiological method of increasing apnoea time in patients with difficult airways. Anaesthesia. 2015;70(3):323-9.

30. Humphreys S, Lee-Archer P, Reyne G, Long D, Williams T, Schibler A. Transnasal humidified rapid-insufflation ventilatory exchange (THRIVE) in children: a randomized controlled trialt. Br J Anaesth. 2017;118(2):232-8.

31. Jagannathan N, Burjek N. Transnasal humidified rapid-insufflation ventilatory exchange (THRIVE) in children: a step forward in apnoeic oxygenation, paradigm-shift in ventilation, or both? $\mathrm{Br} J$ Anaesth. 2017;118(2):150-2.

32. Roca O, Riera J, Torres F, Masclans JR. High-flow oxygen therapy in acute respiratory failure. Respir Care. 2010;55(4):408-13.

\section{Publisher's Note}

Springer Nature remains neutral with regard to jurisdictional claims in published maps and institutional affiliations.
Ready to submit your research? Choose BMC and benefit from:

- fast, convenient online submission

- thorough peer review by experienced researchers in your field

- rapid publication on acceptance

- support for research data, including large and complex data types

- gold Open Access which fosters wider collaboration and increased citations

- maximum visibility for your research: over $100 \mathrm{M}$ website views per year

At $\mathrm{BMC}$, research is always in progress.

Learn more biomedcentral.com/submissions 